\title{
ФАКТОРЫ, ВЛИЯЮЩИЕ НА ДОСТИЖЕНИЕ ЦЕЛЕЙ УСТОЙЧИВОГО РАЗВИТИЯ В ИНДУСТРИАЛЬНО-АГРАРНОМ РЕГИОНЕ
}

\author{
(c) 2021 Андрющенко Сергей Анатольевич \\ доктор экономических наук, профессор \\ Институт аграрных проблем ФГБУН ФИЦ «Саратовский научный центр РАН», Россия, Саратов \\ E-mail: andrapk@yandex.ru \\ (C) 2021 Чередниченко Ольга Александровна \\ кандидат экономических наук, доцент \\ Ставропольский государственный аграрный университет, Россия, Ставрополь \\ E-mail: chered72@mail.ru \\ (c) 2021 Довготько Наталья Анатольевна \\ кандидат экономических наук, доцент \\ Ставропольский государственный аграрный университет, Россия, Ставрополь
}

Статья подготовлена при финансовой поддержке РФФИ, проект 20-010-00375 «Методология формирования и разработка организационно-экономический механизма достижения целей устойчивого развития в национальной агропродовольственной системе»

Проанализированы различные методические подходы к исследованию социальноэкономических и экологических факторов, воздействующих на достижение целей устойчивого развития на региональном уровне. Проведен анализ динамики и взаимосвязи показателей воздействия на окружающую природную среду и здоровья населения Ставропольского края. В качестве обобщающего индикатора устойчивого развития использовался показатель уровня заболеваемости. В числе факторов роста заболеваемости в этом регионе выявлены рост производства в обрабатывающих отраслях промышленности и рост объемов применения минеральных и органических удобрений. Это свидетельствует о необходимости внедрения современных технологий в сельском хозяйстве, связанных с транспортировкой, хранением и внесением удобрений, позволяющих снизить негативное воздействие агрохимикатов на окружающую среду и здоровье населения.

Ключевые слова: устойчивое развитие, индикаторы, население, заболеваемость, сельское хозяйство, промышленность, регрессионный анализ.

\section{Введение}

Среди целей устойчивого развития ключевое место занимают цели прямо или косвенно связанные с производством, распределением и потреблением продуктов питания, воздействием этих процессов на качество жизни населения и состояние окружающей среды. Так в системе целей устойчивого развития (ЦУР) задача 15.3 требует систематического проведения мероприятий по предотвращению опустынивания и восстановлению деградированных земли и почвы, что является необходимым для роста производства продукции растениеводства - основы производства продуктов питания. Также необходимо радикально сократить послеуборочные и другие потери продовольствия в производственно-сбытовых цепочках на всех стадиях производства сельскохозяйственного сырья, о чем говорится в задаче 12.3 [1]. Основная задача развития агропродовольственного комплекса мира и отдельных стран состоит в максимальном расширении применения устойчивых методов ведения сельского хозяйства (задача 2.4), что должно привести к:

- повышению устойчивости сельского хозяйства к воздействию климатических факторов, что выражается индикаторами колебаний урожайности и производства валовой продукции отрасли;

- повышению продуктивности использования земельных и других ресурсов, что выражается индикаторами урожайности и производства продукции сельского хозяйства в расчете на 1 га сельскохозяйственных угодий или пашни; 
- росту производства продовольственной продукции, что выражается индикаторами темпов роста производства, роста производства в расчете на 1 жителя, роста потребления важнейших видов продовольствия, роста уровня и качества жизни сельского населения;

- сохранению развития экосистем, что характеризуется сохранением разнообразия растительного и животного мира, а также показателями объемов выбросов загрязняющих веществ в атмосферу и сброса в водоемы;

- постепенному улучшению качества земель $u$ почв, в большинстве регионов РФ речь идет о снижении темпов снижения содержания питательных веществ и гумуса в пахотных землях.

Формирование организационно-экономического механизма достижения целей устойчивого развития требует изучения факторов, воздействующих на достижение каждой цели, и обоснования экономических и организационных инструментов, воздействующих на каждый из факторов [2]. Исследования этой проблемы проводятся во многих научных центрах, они показали, что применение регрессионных уравнений позволяет выявить степень воздействия отдельных факторов на индикаторы устойчивого развития. Множественность целей устойчивого развития требует или выбора в отдельных случаях приоритетной цели или формирования интегрального показателя, характеризующего повышение устойчивости. Так Б.Ли и др. [3] предложили метод оценки показателей циркулярного сельского хозяйства и анализа факторов, воздействующих на динамику интегрального показателя, с целью определения динамики движения отрасли к достижению устойчивого развития. После расчета значений интегрального показателя за ряд лет для провинции Хэнань был проведен регрессионный анализ влияния отдельных факторов на общий показатель; как показали расчеты, смена сельскохозяйственных технологий оказала наибольшее положительное влияние на движение провинции к устойчивому развитию, негативное воздействие зафиксировано для фактора урбанизации.

В качестве обобщающих индикаторов устойчивого развития также часто используются показатели, связанные со здоровьем населения, например продолжительность жизни или уровень заболеваемости [4]. Масштабный проект осуществляется в Самарской области, где в Институте экологии Волжского бассейна
РАН разработана совокупность экспертных информационных систем (ЭИС) для территорий разной масштабности, предназначенных для оценки воздействия окружающей природной среды на здоровье населения [5]. Применение ЭИС «REGION-VOLGABAS» показало, что на состояние здоровья людей на урбанизированных территориях Волжского бассейна кроме социально-экономических факторов значительное влияние оказывают неблагоприятные факторы природной среды, влияние экологических факторов на здоровье людей оценивается на уровне 15-20\%. В частности, рассчитанные регрессионные уравнения показали, что такой показатель здоровья населения как «временная нетрудоспособность» может сократиться в этой части Российской Федерации на 1,3\% при снижении показателей выбросов в атмосферу и сброса загрязненных вод в расчете на одного жителя на 20\%. Статистически значимая связь была выявлена учеными НИУ ВШЭ при сопоставлении данных по промышленным центрам о заболеваемости злокачественными новообразованиями и выбросами диоксида серы. Этот загрязнитель не причислен к канцерогенам, рост его концентрации связан с ростом выбросов других загрязняющих веществ, вредных для здоровья [4].

В качестве примера применения регрессионного анализа для оценки факторов, воздействующих на показатели, характеризующие цели устойчивого развития, можно привести опыт Института экономики Уральского отделения РАН, где была проведена серия исследований факторов, влияющих на продолжительность жизни населения России - ключевого показателя устойчивого развития. На федеральном уровне с помощью статистических методов математического анализа была показана достаточно тесная связь между показателями заболеваемости и ожидаемой продолжительности жизни населения. На региональном уровне расчеты проводились для промышленно развитых регионов России, с их помощью было установлено, что с концентрацией хозяйственной деятельности и населения значительно возрастает воздействие антропогенных факторов, таких как выбросы загрязняющих веществ в атмосферу, на здоровье и жизнь людей [6]. Также на примере Свердловской области было исследовано влияние различных видов загрязнения окружающей среды на ожидаемую продолжительность жизни населения, как важнейшего индикатора устойчивого 
развития. Однофакторные регрессионные модели показали высокую степень зависимости повышения продолжительности жизни в этом регионе от сокращения выбросов в атмосферу загрязняющих веществ стационарными источниками и сбросов загрязненных сточных вод [7]. В целом, расчеты российских и зарубежных ученых показали возможность и целесообразность применения регрессионного анализа для оценки влияния факторов на показатели достижения целей устойчивого развития на региональном уровне.

Цель представленного исследования состояла в обосновании и апробации методов статистического анализа при определении приоритетных социально-экономических факторов, влияющих на достижение целей устойчивого развития в субъектах Российской Федерации с развитым промышленным и сельскохозяйственным производством.

\section{Методика исследований}

Для оценки значимости и интерпретации результатов регрессионного анализа в данной работе апробировано применение межрегиональных сопоставлений с целью определения проблемных мест в управлении исследуемых регионов, требующих приоритетного внимания [8]. Состав показателей, используемых для межрегиональных сопоставлений должен отвечать ряду требований, в том числе: отражать основные аспекты исследуемой цели устойчивого развития и воздействующие на нее факторы, показывать прослеживаемую взаимосвязь показателей, характеризующих как релевантные факторы, так и цели устойчивого развития.

В данном исследовании для сравнения были выбраны два соседних региона: Ставропольский край и Краснодарский край. Оба региона располагают значительными земельными ресурсами и занимают ведущие места в Российской Федерации по объему производства сельскохозяйственной продукции. На сопоставимость природно-климатических и социальноэкономических условий аграрного производства указывают показатели динамики сельскохозяйственного производства (рис. 1) и темпов роста валового сбора зерна (рис. 2). Рис. 2 также показывает, что за последние два десятилетия в сравниваемых регионах наблюдался значительный рост производства продукции растениеводства, при этом темпы роста подвержены значительным колебаниям. Также в сравниваемых реги- онах наблюдался рост производства продукции животноводства. В Краснодарском крае в 20112014 гг. случилось кратковременное снижение продукции животноводства, вызванное эпидемией африканской чумы свиней, в последующие годы темпы роста производства в подотрасли восстановились. Потребление мяса на душу населения в обоих регионах росло в XXI веке среднероссийскими темпами и достигло уровня медицинских норм, что свидетельствует об относительно благополучном среднем уровне жизни населения.

\section{Результаты исследований}

Рост производства продовольственной продукции в Ставропольском и Краснодарском краях объясняется ростом фондооснащенности и ростом применения минеральных и органических удобрений. Сельскохозяйственные организации этих двух регионов занимают лидирующие позиции в России по объемам внесения минеральных и органических удобрений (рис. 3 и 4). Так, на долю Краснодарского края в 2018 г. приходилось $12 \%$ общероссийского объема внесенных минеральных удобрений и 5\% органических удобрений; на долю Ставропольского края - 9\% минеральных удобрений и $12 \%$ органических удобрений [9].

В 2000-2019 г. в Ставропольском крае и Красноярском крае наблюдались значительные различия в тенденциях роста загрязнения атмосферного воздуха и водоемов. За этот период в Ставропольском крае объемы выбросов загрязняющих веществ в атмосферный воздух, отходящих от стационарных источников, характеризуются равномерным снижением в 2000-2009 гг. и столь же равномерным ростом в 2010-2019 гг. (рис. 5); показатели сброса загрязненных сточных вод в поверхностные водные объекты за эти годы также изменялись достаточно плавно (рис. 6).

В то же время в Краснодарском крае зафиксированные государственной статистикой объемы загрязнения атмосферного воздуха подвергались радикальным колебаниям, особенно в 2016-2017 гг. (рис. 5). Значения показателя загрязнения водоемов в Краснодарском крае в 2000-2019 гг. подвергались значительным колебаниям и при этом примерно в 5 раз превосходили значения аналогичного показателя в Ставропольском крае (рис. 6). Равномерные изменения значений показателей загрязнения окружающей среды в Ставропольском крае сви- 


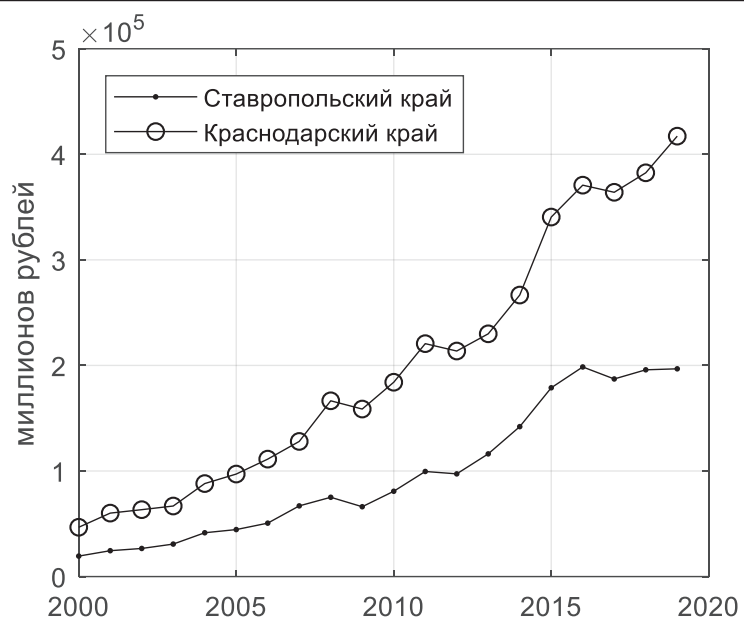

Рис. 1. Продукция сельского хозяйства (в хозяйствах всех категорий; в фактически действовавших ценах; млн руб.)

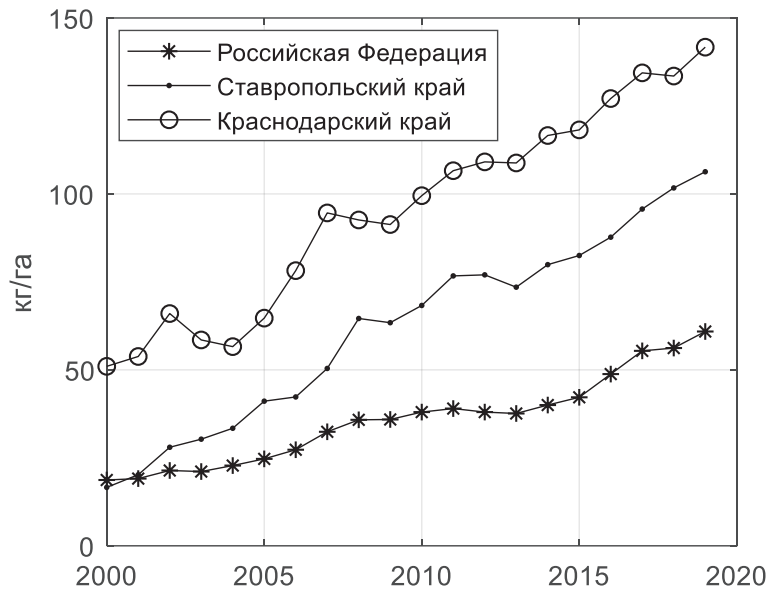

Рис. 3. Внесено сельскохозяйственными организациями минеральных удобрений (в пересчете на $100 \%$ питательных веществ) кг/га

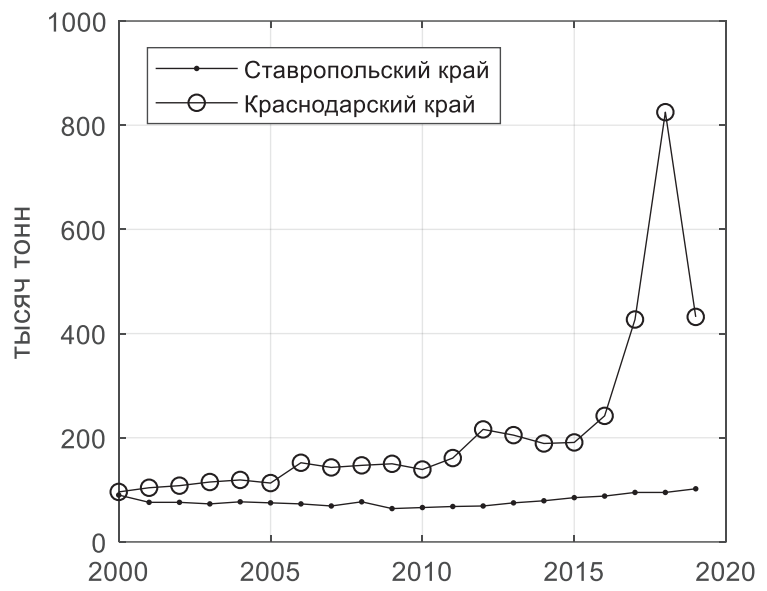

Рис. 5. Выбросы загрязняющих веществ в атмосферный воздух, отходящих от стационарных источников (тысяч тонн)

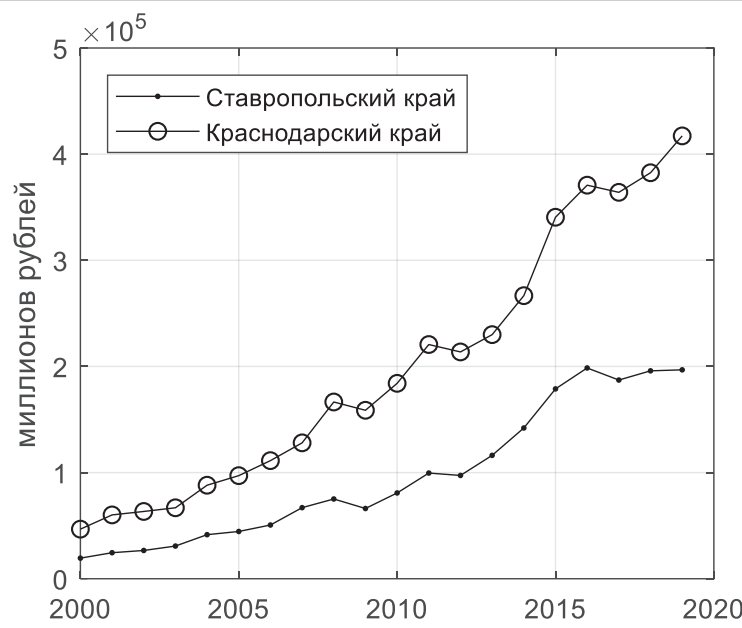

Рис. 2. Валовой сбор зерна в весе после доработки (в хозяйствах всех категорий; тысяч тонн)

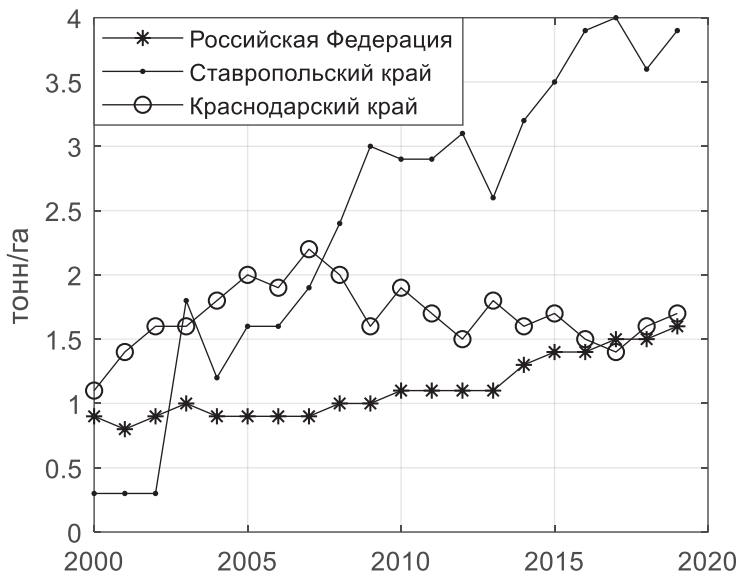

Рис. 4. Внесено сельскохозяйственными организациями органических удобрений, тонн/га

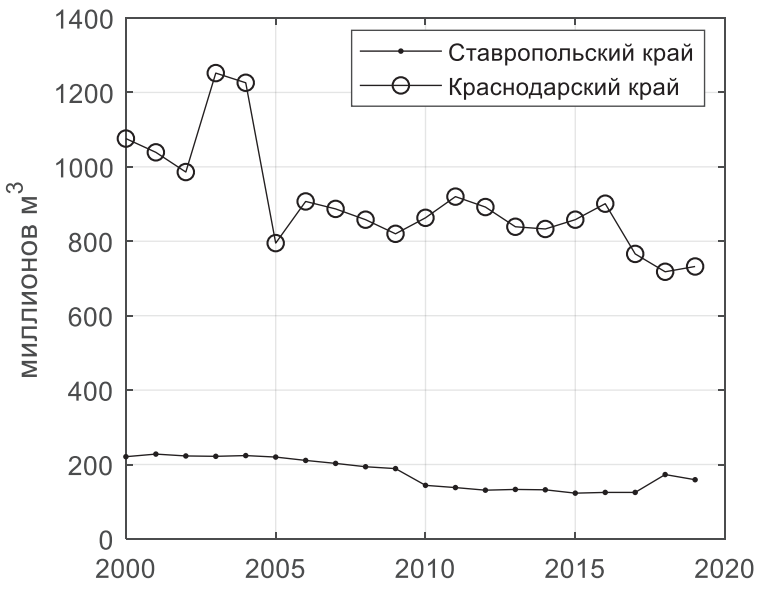

Рис. 6. Сброс загрязненных сточных вод в поверхностные водные объекты (миллионов кубических метров) 
детельствуют о возможности использовать его в качестве примера при исследовании воздействия социально-экономических и экологических факторов на достижение целей устойчивого развития в регионах с развитыми промышленностью и сельским хозяйством.

Приведенные выше данные свидетельствуют, что производственная деятельность, в том числе в сельском хозяйстве, оказывают значительное воздействие на окружающую среду Краснодарского и Ставропольского краев, в связи с чем возникает вопрос о последствиях такого воздействия для здоровья населения регионов. Одним их проявлений негативных последствий может быть рост заболеваемости населения.

На рис. 7 показана динамика изменения показателя числа заболеваний органов дыхания в расчете на 1000 жителей с 2004 по 2019 гг. Число таких заболеваний в рассматриваемых регионах примерно на одну треть меньше, чем в среднем по России, но росло примерно теми же темпами, что и среднероссийский показатель. Аналогичная картина складывается по динамике удельного показателя числа заболеваний системы кровообращения (рис.8) [10. С.429, 427], только число таких заболеваний на порядок меньше, чем число заболеваний органов дыхания.

В ходе исследования была проверена гипотеза о наличии взаимосвязи между ростом применения таких потенциальных загрязнителей, как минеральные и органические удобрения, и ростом заболеваемости населения. Однофакторная линейная регрессионная модель влияния роста удельных показателей внесения мине-

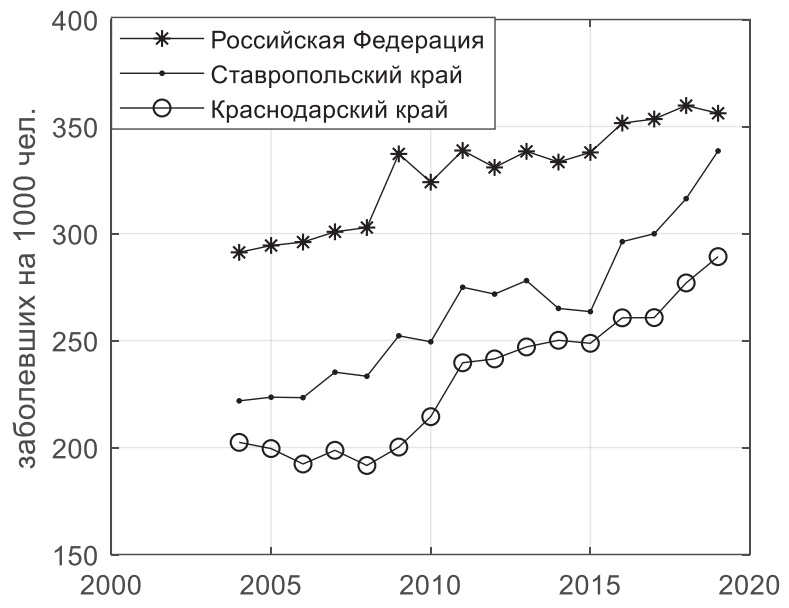

Рис. 7. Болезни органов дыхания на 1000 человек населения ральных удобрений на заболеваемость органов дыхания в Ставропольском крае (рис. 9) имеет следующий вид:

$$
y=1.54 x+155 \ldots R^{2}=0.9324
$$

где $y$ - число заболевших органами дыхания на 1000 человек за год;

$x$ - внесено минеральных удобрений, кг/га.

Аналогичная зависимость была получена при оценке влияния роста внесения органических удобрений на заболеваемость населения. Показатели внесения минеральных и органических удобрений выбраны в качестве факторов для модели как типичные техногенные факторы, характерные для субъектов Российской Федерации с развитой промышленностью и интенсивным сельским хозяйством. Однотипная взаимосвязь выявлена для показателей динамики производства продукции обрабатывающих производств и числа заболеваний органов дыхания (заболевших на 1000 человек) в Ставропольском крае (рис.10). В данном случае, заболевания органов дыхания выбраны в качестве индикатора состояния здоровья населения как наиболее массовый вид заболеваний, охватывающий 20-40\% населения в год. При этом значение показателя заболеваемости на уровне 20\% можно рассматривать как фоновое, вызванное естественными климатическими факторами (рис. 9 и 10). Рост заболеваний органов дыхания в крае в 2010-2019 гг. может быть объяснен ростом интенсификации промышленного и сельскохозяйственного производства (рис. 3, 4, 5).

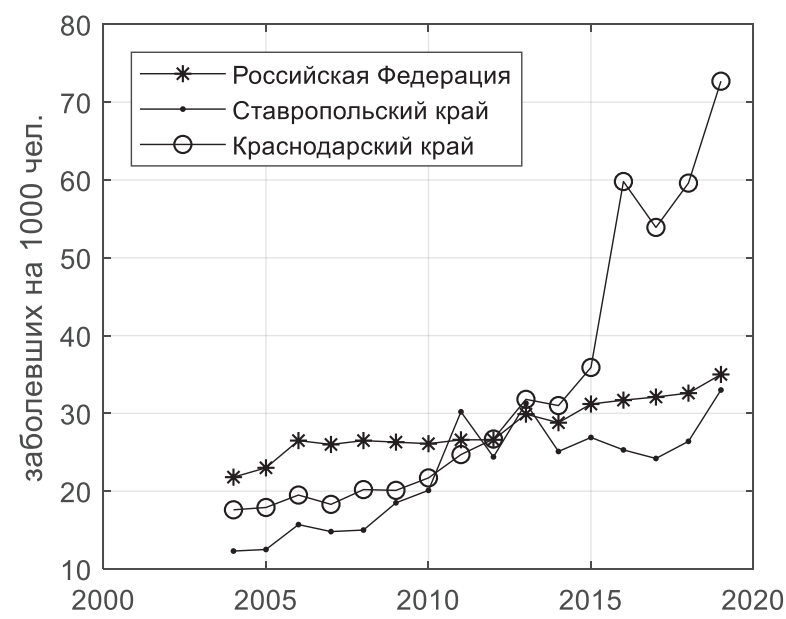

Рис. 8. Болезни системы кровообращения на 1000 человек населения 


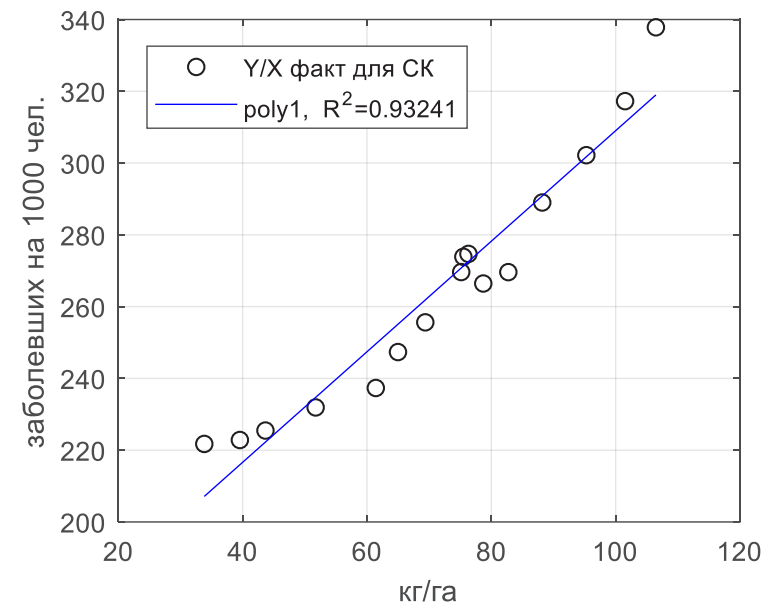

Рис. 9. Влияние удельных показателей внесения минеральных удобрений (кг/га) на число заболеваний органов дыхания (заболевших на 1000 человек)

Ставропольский край может рассматриваться как представительный пример воздействия социально-экономических и экологических факторов на достижение целей устойчивого развития. В Ставропольском крае отмечается рост заболеваемости, регрессионный анализ показал, что к числу возможных факторов роста заболеваемости относятся рост производства в обрабатывающих отраслях промышленности и рост объемов применения минеральных и органических удобрений. Динамика этих факторов указывает на то, что рост производства как в сельском хозяйстве, так и в промышленности края достигается при использовании неизменных технологий.

\section{Заключение}

В научной литературе используются различные методические подходы к исследованию факторов, воздействующих на достижение целей устойчивого развития, и к интерпретации полученных результатов. Одним из самых распространенных методов является регрессионный анализ. Проведенный с помощью этого метода анализ статистических данных по

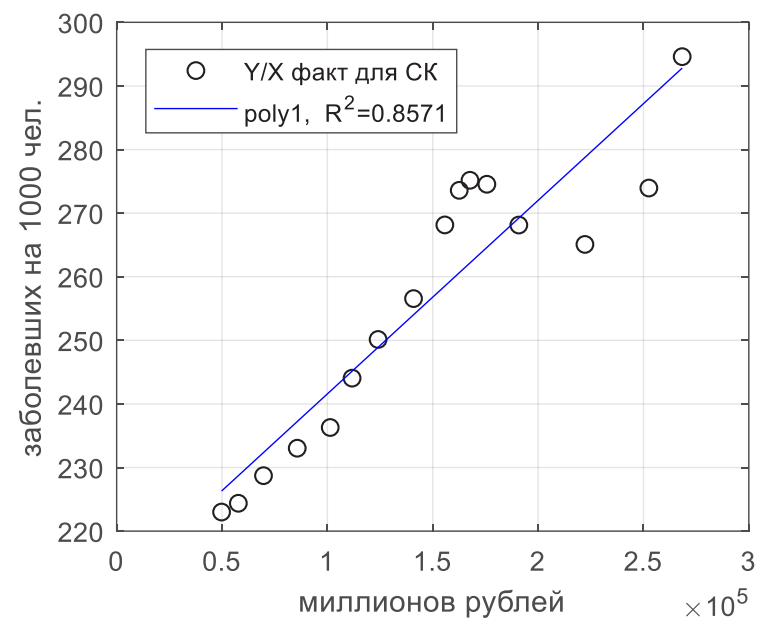

Рис. 10. Влияние динамики производства продукции обрабатывающих производств (в фактически действовавших ценах) на число заболеваний органов дыхания (миллионов рублей на 1000 человек)

Ставропольскому краю показал равномерные изменения значений показателей загрязнения окружающей среды и заболеваемости населения. Проведенные межрегиональные сопоставлений свидетельствуют о возможности использовать информацию по Ставропольскому краю в качестве примера при исследовании воздействия социально-экономических и экологических факторов на достижение целей устойчивого развития в регионах с развитыми промышленностью и сельским хозяйством. К числу возможных факторов роста заболеваемости в этом регионе относятся рост производства в обрабатывающих отраслях промышленности и рост объемов применения минеральных и органических удобрений. Это свидетельствует о необходимости внедрения современных технологий в сельском хозяйстве, связанных с транспортировкой, хранением и внесением удобрений, позволяющих снизить негативное воздействие агрохимикатов на окружающую среду и здоровье населения. Также необходим поиск мер в промышленности по снижению выбросов загрязняющих веществ в атмосферный воздух и сбросов в водоемы. 


\section{Библиографический список}

1. Богданович А.Ю., Липка О.Н. Синергия климатической глобальной цели устойчивого развития и национального плана адаптации в России // Проблемы экологического мониторинга и моделирования экосистем. 2020. Т. 31. № 3-4. С. 7-32.

2. Довготько Н.А., Андрющенко С. А., Чередниченко О.А., Скиперская Е. В. Опыт Европейского Союза по реализации целей устойчивого развития в сельском хозяйстве и возможности его применения в России // Международный сельскохозяйственный журнал. 2021. № 1 (379). С. 74-80.

3. Li, B.; Feng, Y.; Xia, X.; Feng, M. Evaluation of China's Circular Agriculture Performance and Analysis of the Driving Factors. Sustainability 2021, 13, 1643. https://doi.org/10.3390/su13041643.

4. Аистов А.В., АлександроваЕ.А. Здоровье населения и загрязнение окружающей среды: региональные аспекты // Регион: экономика и социология. 2018. № 2 (98). С. 216-240.

5. Лазарева Н.В., Розенберг Г. С., Аристова М.А., Костина Н.В. Здоровье среды и здоровье населения: модели, прогноз, ущербы // Вестник медицинского института «РЕАВИЗ»: реабилитация, врач и здоровье. 2020 . № 2 (44). С. 112-122.

6. Козлова О.А., ТухтароваЕ.Х., ИлинбаеваЕ.А. Методические вопросы оценки устойчивости трудоспособного населения к негативному экологическому воздействию // Экономические и социальные перемены: факты, тенденции, прогноз. 2017. Т. 10. № 4. С. 212-227.

7. озлова О.А., Шеломенцев А. Г., Трушкова Е. А. Влияние экологических факторов на показатели ожидаемой продолжительности жизни населения Свердловской области // Социальные аспекты здоровья населения. 2018. № 6 (64). С. 12.

8. Денисов Н. А. Сопоставление качества жизни населения регионов России на основе интегрального показателя // Уровень жизни населения регионов России. 2005. № 1 (83). С.21-30.

9. Росстат. Внесение удобрений под урожай 2018 года и проведение работ по химической мелиорации земель. http://old.gks.ru/wps/wcm/connect/rosstat_main/rosstat.ru. Доступ 09.03.2021.

10. Регионы России. Социально-экономические показатели. 2020: Стат. сб. / Росстат. - М., 2020. - 1242 с. 